\title{
Thermal conductivity of polycrystalline aluminum nitride (AIN) ceramics
}

\section{(Condutividade térmica de cerâmicas policristalinas de nitreto de alumínio $($ AlN))}

\author{
A. Franco Júnior ${ }^{1}$, D. J Shanafield ${ }^{2}$ \\ 'Núcleo de Pesquisa em Química, Universidade Católica de Goiás, \\ C.P. 86, Setor Universitário \\ Goiânia, GO, Brazil 74605-010 \\ franco@ucg.br \\ ${ }^{2}$ Center for Ceramic Research, Rutgers University, P.O. Box 909, \\ Piscataway, NJ 08855-909, USA
}

\begin{abstract}
In general, polycrystalline ceramics exhibit lower thermal conductivities than their associated single crystals. For instance, at $300 \mathrm{~K}$, the theoretical thermal conductivity of single crystal aluminum nitride (AIN) is $319 \mathrm{~W} / \mathrm{m}-\mathrm{K}$, whereas, the values measured for polycrystalline AlN ceramics range from $17 \mathrm{~W} / \mathrm{m}-\mathrm{K}$ to $285 \mathrm{~W} / \mathrm{m}-\mathrm{K}$. This variation is not unusual for polycrystalline ceramics. The variability is strongly dependent upon the purity of the starting materials and the details of sintering process. The process is important since it influences the microstructure and thus influences the conduction mechanism. In this paper we present the causes of this variation and how it can be controlled.
\end{abstract}

Keywords: Aluminum nitride, thermal conductivity, thermal conduction mechanism

\section{Resumo}

Em geral, cerâmicas policristalinas apresentam condutividade térmica mais baixa do que seus equivalentes monocristais. Por exemplo, a $300 \mathrm{~K}$, a condutividade térmica teórica de monocristais de nitreto de alumínio (AlN) é $319 \mathrm{~W} / \mathrm{m}-\mathrm{K}$, enquanto que, os valores medidos variam desde $17 \mathrm{~W} / \mathrm{m}-\mathrm{K}$ a $285 \mathrm{~W} / \mathrm{m}$-K. Esta variação é comum em cerâmicas policristalinas. A variação é fortemente dependente do grau de pureza dos materiais precursores e detalhes dos processos de sinterização. O processo de sinterização é importante porque ele influencia a microestrutura e esta o mecanismo de condutividade. Neste artigo nós apresentamos as causas desta dependência e como ela pode ser controlada.

Palavras-chave: Nitreto de alumínio condutividade térmica, mecanismo da condutividade.

\section{INTRODUCTION}

Most of the applications of polycrystalline ceramics take advantage of either their thermal insulation or thermal conducting behavior. The utility of the ceramic is fixed by the rate of heat transfer through the ceramic body under a given temperature gradient. The basic equation describing this relationship is given by [1]

$$
\frac{d h}{d t}=-k \frac{d T}{d x}
$$

where $\frac{d h}{d t}$ is the amount of heat flowing normal to a unit area in time $d t$, and $\frac{d T}{d x}$ is the temperature gradient along the unit direction $d x$. The proportionality factor $k$ is known as thermal conductivity. The minus sign indicates that the heat always flows from hot to cold regions.

The more general equation for three-dimensional heat flow is written as

$$
\vec{U}=-k \nabla T
$$

where $\vec{U}$ is a heat flux vector, and $k$ is a second rank symmetric tensor, the thermal conductivity tensor, with at most, six independent terms [2]. For glasses, cubic crystals, and most polycrystalline materials, the thermal conductivity is isotropic, thus the thermal conductivity tensor can be treated as a scalar.

In dielectric solids the conduction of heat can be viewed as either the propagation of anharmonic elastic waves through a continuum or the interaction between quanta of thermal energy or phonons [1]. Thus the thermal conductivity can be 
represented, in a general form, by

$$
k=\frac{1}{3} \cup \int_{0}^{\omega} c(\omega) l(\omega) d \omega
$$

where $v$ is the phonon group velocity, $c(\omega)$ is the phonon contribution of the volumetric heat capacity, and $l(\omega)$ is the phonon mean free path $[1,3]$. At low temperatures, $k$ is limited through $c(\omega)$ by the Debye $\mathrm{T}^{3}$ law [3]. At high temperatures, $l(\omega)$ decreases because of intrinsic, phonon-phonon interactions or Umklapp scattering. Thus, $k$ exhibits a maximum as a function of temperature [4].

In addition to intrinsic phonon scattering, various imperfections can introduce anharmonicities in the lattice and thus cause extrinsic phonon scattering. Among these are: vacancies, interstitials, isotropic mass differences, substitutional impurities and dislocations [1]. Abeles examined the scattering cross-section associated with impurity atoms [5]. He found that at intermediate temperatures the larger the scattering cross-section, the lower the thermal conductivity. At room temperature, the phonon mean free path is somewhat lower than $100 \AA$. At very high temperatures, $k$ is proportional to $\mathrm{T}^{-1}$, and the mean free path decreases to a value near the lattice spacing [3]. Hence, at high temperatures, the conductivity is generally independent of phonon-defect interactions and crystallite size. At intermediate temperatures, $k$ is proportional to $\mathrm{T}^{-0.5}$, and $k$ is dominated by phonon-defect interactions [3]. At very low temperatures, the phonon mean free path is of the same magnitude as the crystallite size, and boundary effects predominate [1, 3-4]

\section{HIGH THERMAL CONDUCTIVITY MATERIALS}

Anharmonicities in lattice vibrations increase as the difference in atomic mass of the constituents increases. As a result, the thermal conductivity is a maximum for simple crystal structures and decreases as the atomic masses of the components become more different. It is based upon such knowledge that Slack [6] developed four rules for identification of crystals with high thermal conductivity, i.e., the crystal should have (1) low atomic mass, (2)strong bonding,(3) simple crystal structure, and (4) low anharmonicity. A review of the literature shows that only a few crystals fall into this category. The majority are adamantine (tetrahedrally bonded, diamondlike) compounds such as diamond, boron nitride, silicon carbide, silicon, beryllium oxide, aluminum nitride, and gallium phosphide. At $300 \mathrm{~K}$, the thermal conductivity of this series decreases from $2000 \mathrm{~W} / \mathrm{m}-\mathrm{K}$ for diamond to $100 \mathrm{~W} / \mathrm{m}-\mathrm{K}$ for GaP. Slack identified twelve diamond-like, a few boron carbide-type, and two graphite crystal structures which exhibited high thermal conductivity [6]. Analyses of other structures showed no additional candidates.

The demand for increasing circuit density and power on silicon chips makes heat dissipation a critical issue in circuit design. Heat dissipation through the substrate is a simple, yet convenient means of lowering circuit temperatures. As a result, materials with high thermal conductivity are highly desirable for substrate applications. Table I compares the typical properties of four ceramic materials which are currently being used in electronic substrate applications [7]. Due to is unique blend of physical properties, i.e., high thermal conductivity, high electrical resistivity, and close thermal expansion coefficient match to silicon, aluminum nitride (AIN) has been identified a key substrate material for high power, electronic devices.

Although the theoretical thermal conductivity of AlN at room temperature is believed to be as high as $319 \mathrm{~W} / \mathrm{m}-\mathrm{K}$ [4], the values measured for polycrystalline AIN ceramics range from as low as $17 \mathrm{~W} / \mathrm{m}-\mathrm{K}$ to as high as $285 \mathrm{~W} / \mathrm{m}-\mathrm{K}$. This range is not atypical of many polycrystalline ceramics. Like single crystals, lattice defects play a dominant role in the

Table I - Relevant physical properties of four ceramic materials used for electronic substrates.

[Tabela I - Propriedades físicas relevantes de quarto materiais cerâmicos usados em substratos eletrônicos].

\begin{tabular}{|c|c|c|c|c|}
\hline PHYSICAL PROPERTY & AIN & $\mathrm{SiC}$ & BeO & $\mathrm{Al}_{2} \mathrm{O}_{3}$ \\
\hline Thermal conductivity $(\mathrm{W} / \mathrm{m}-\mathrm{K})$ at $25^{\circ} \mathrm{C}$ & $170-220$ & 150 & $250-300$ & $20-30$ \\
\hline \multirow{2}{*}{\multicolumn{5}{|c|}{$\begin{array}{l}\text { Thermal expansion coefficient } \\
\left(\times 10^{-6} /{ }^{\circ} \mathrm{C}\right) \text { from } 25-400{ }^{\circ} \mathrm{C}\end{array}$}} \\
\hline & & & & \\
\hline (TCE of Si: $3.5-4 \times 10^{-6} /{ }^{\circ} \mathrm{C}$ ) & 4.3-4.6 & 3.7 & $7.5-8.0$ & $6.7-7.3$ \\
\hline Dielectric constant at $25^{\circ} \mathrm{C}$ and $1 \mathrm{MHz}$ & $8.8-8.9$ & $40-42$ & $6.5-6.7$ & $8.5-8.9$ \\
\hline Dielectric loss $\left(\mathrm{x10}^{-4}\right)$ at $1 \mathrm{MHz}$ & $1-5$ & 500 & $1-5$ & $2-3$ \\
\hline Dielectric strength $(\mathrm{kV} / \mathrm{cm})$ at $25^{\circ} \mathrm{C}$ & $140-170$ & 0.7 & 100 & 100 \\
\hline Electrical resistivity $(\Omega . \mathrm{cm})$ at $25^{\circ} \mathrm{C}$ & $>10^{14}$ & $>10^{14}$ & $>10^{14}$ & $>10^{14}$ \\
\hline Density $\left(\mathrm{g} / \mathrm{cm}^{3}\right)$ & 3.26 & 3.21 & 3.01 & 3.97 \\
\hline Flexural strength $\left(\mathrm{kg} / \mathrm{cm}^{2}\right)$ & $4000-5000$ & 4500 & 2500 & 3000 \\
\hline Young's modulus (GPa) & 343 & 460 & 378 & 378 \\
\hline
\end{tabular}


thermal conductivity of polycrystalline ceramics. Furthermore, polycrystalline ceramics have reduced thermal conductivities due to two key factors: (1) the random orientation of the individual grains and (2) the random distribution of discrete secondary phases.

\section{ALUMINUM NITRIDE-STRUCTURE}

Aluminum nitride (AIN) is mostly covalent material, ca. $75 \%$ and crystallizes under the wurtzite structure $\mathrm{a}=3.111 \AA$ and $\mathrm{c}=4.978 \AA, \mathrm{c} / \mathrm{a}=1.600 \AA$, group $P 6_{3} m c-C_{6 v}^{4}$ that is, hexagonal close packing of the anions with the cations filling half the tetrahedral sites. The unit cell contains two anions, one at the origin and one inside the cell. Their coordinates are:

$0,0,0$ and $\frac{1}{3}, \frac{2}{3}, \frac{1}{2}$ (Fig. 1). Close packed layers occurs at the basal plane i.e. at $c=0$ and at $c=\frac{1}{2}$ and therefore that stacking sequence is hexagonal...ABABA....

The crystal structure can be modified into a variety of polytypes with the addition of impurity elements. The material forms limited solid solutions with elements such as oxygen, carbon, and silicon. At $1.00 \mathrm{~atm}$ of pressure, AlN does not melt, but dissociates significantly above $2230^{\circ} \mathrm{C}$. Aluminum nitride does not occur naturally; therefore, it must be synthesized by high-temperature reaction.

\section{CONDUCTIVITY OF COMPOSITE MICROSTRUCTURES}

Most ceramic materials are composed of mixtures of one or more phases. In some instances, the second phase may be porosity while in may be discrete grain boundary phases associated with impurities or processing additives. The resulting conductivity of the composite body depends on the amounts, arrangement, and individual thermal conductivities of the various components. Unlike solid solutions, the thermal

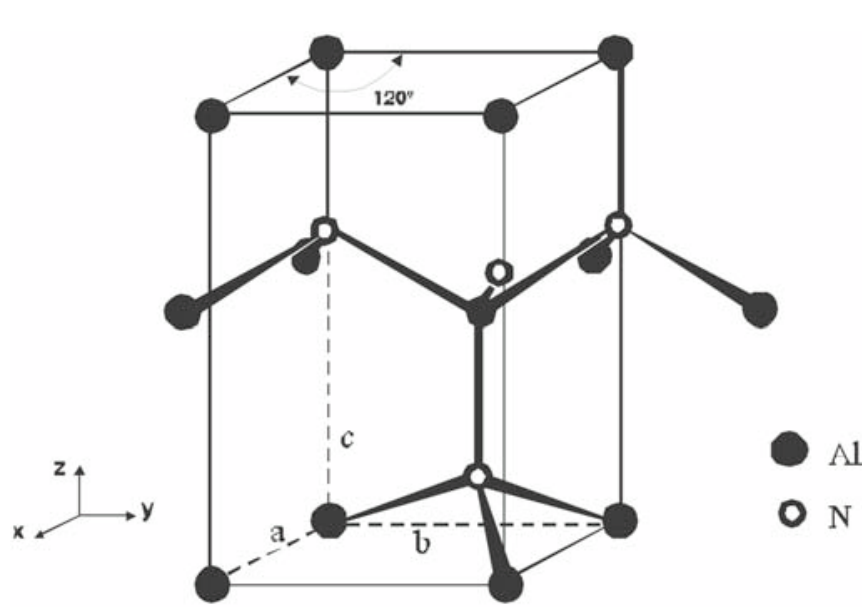

Figure 1: Aluminum nitride structure.

[Figura 1: Nitreto de Alumínio - estrutura wurtizte]. conductivity of the composite lies between that of its two end members.

There are several theoretical models for predicting the thermal conductivity of composite materials. In this discussion, two simple microstructures will be used to illustrate the net effects of a discrete secondary phase dispersed in a contiguous matrix phase as $\mathrm{k}_{\mathrm{m}}>\mathrm{k}_{\mathrm{d}}$ and $\mathrm{k}_{\mathrm{m}}<\mathrm{k}_{\mathrm{d}}$. The relations describing the conductivity of such structures were originally derived by Maxwell [1], in 1904. Euken later applied the equations to thermal conductivity [1].

If the thermal conductivity of the matrix phase is $\mathrm{k}_{\mathrm{m}}$ and the thermal conductivity of the dispersed phase is, $\mathrm{k}_{\mathrm{d}}$ then the composite thermal conductivity can be given as:

$$
K_{\text {comp }}=k_{m}\left[\frac{1+2 v_{d}\left(1-\frac{k_{m}}{k_{d}}\right) /\left(\frac{2 k_{m}}{\left(k_{d}+1\right)}\right)}{1-v_{d}\left(1-\frac{k_{m}}{k_{d}}\right) /\left(\frac{k_{m}}{\left(k_{d}+1\right)}\right)}\right]
$$

Where $v_{d}$ is the volume fraction of the spherical, dispersed phase.

This model can be used to describe two extreme microstructures, i.e., one in which the higher conducting phase is contiguous, and one in which the lower conducting phase is contiguous. Fig. 2 compares the influence of increasing volume fractions of the dispersed phase. Obviously, a low conducting, highly wetting secondary phase can significantly reduce the thermal conductivity of a high $\mathrm{k}$ medium. The importance of these results can be directly related to polycrystalline AIN ceramics. Most polycrystalline AIN substrates contain small amounts of secondary phases, mainly oxides. The thermal conductivity of the oxide phase is lower than the AIN matrix. If the AIN phase is contiguous with a finely dispersed secondary oxide phase, then the resulting thermal conductivity will only be slightly influenced by the oxide phase. In contrast, if the AlN grains are uniformly coated with a low thermal conducting oxide phase, then the resulting thermal conductivity will be

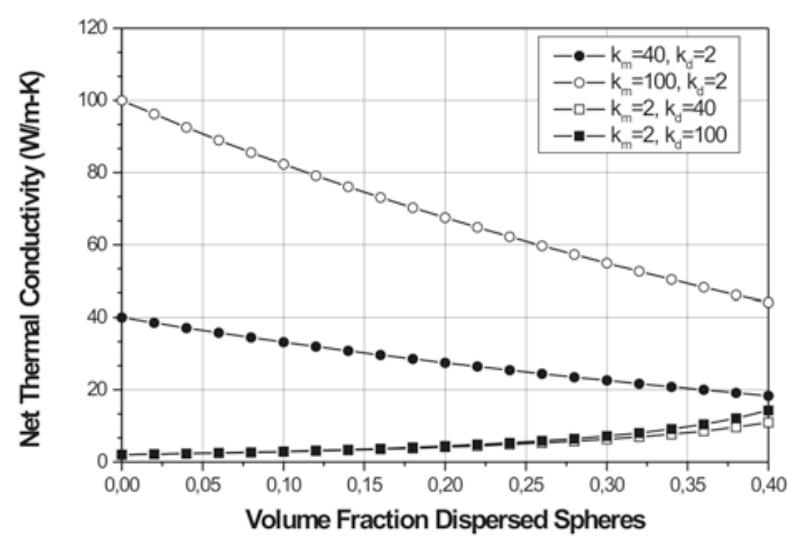

Figure 2: Calculated net thermal conductivity for the dispersed phase microstructure. $\mathrm{k}_{\mathrm{m}}<\mathrm{k}_{\mathrm{d}}$ and $\mathrm{k}_{\mathrm{m}}<\mathrm{k}_{\mathrm{d}}$.

[Figura 2: Condutividade térmica líquida calculada em relação a fase dispersa da microestrutura. . $\mathrm{k}_{\mathrm{m}}<\mathrm{k}_{\mathrm{d}}$ e $\mathrm{k}_{\mathrm{m}}<\mathrm{k}_{\mathrm{d}}$.]. 
significantly influenced by the oxide phase. The latter case is similar to that seen in the thermal enhancement of plastic molding compounds [8].

There have been a number of modifications of the Maxwell model to extend its volume range of applications and to account for different shapes of the dispersed particles. However, no one approximates the real geometries that may be found in multiphase ceramic systems and their characteristics are essentially similar to Maxwell's model.

A porous solid can be considered a composite material in which the second phase is air, some other fluid or a vacuum. At low temperatures the thermal conductivity of the second phase can be generally neglected as compared with that of the solid. If the porosity is the dispersed phase, Equation D becomes, for $\mathrm{k}_{\mathrm{d}}=0$,

$$
K_{\text {comp }=} k_{m}\left[\frac{1-\Phi}{1+\frac{1}{2} \Phi}\right]
$$

where $\phi$ is the volume fraction of spherical pores. For small $\phi$, equation $\mathrm{E}$ can be approximated by $[1,7]$

$$
K_{c o m p=} k_{m}\left[1-\frac{1}{3} \Phi\right]
$$

Equation $\mathrm{F}$ is valid only for spherical pores. Experimentally results cam be often fitted to an equation of the type

$$
K_{c o m p=} k_{m}[1-\beta \Phi]
$$

where $\beta$ is a parameter related to the pore geometry [1,7]. If the shape of the pores is not known or it cannot be approximated by a simple model, Equation $\mathrm{F}$ can be used to obtain an adequate estimate of the effect of porosity on the thermal conductivity of the solid.

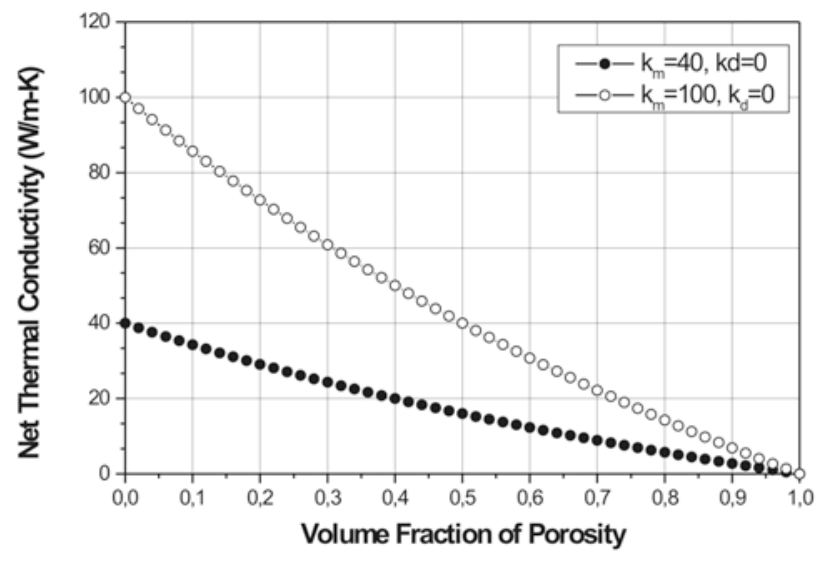

Figure 3: The effect of porosity on thermal conductivity of AIN. [Figura 3: O efeito da porosidade na condutividade térmica de AlN].
In Fig. 3 is shown the effect of porosity dispersed phase (Equation E) on the thermal conductivity of a porous solid considered as a composite material in which the second phase is a fluid, for $\mathrm{k}_{\mathrm{d}}=0$. As the volume fraction of the porosity increases the thermal conductivity decreases and become zero when $\phi=1$.

\section{MEANS OF ACHIEVING THERMAL CONDUCTIVITY IN CERAMICS}

The variation which is observed amongst the thermal conductivities of polycrystalline ceramics is strongly dependent upon the purity of the starting materials and details of the fabrication process. This section will focus on the causes of this variation and how they can be controlled. For illustrative purposes, the discussion will focus o aluminum nitride.

The key technological areas which have contributed most significantly to enhanced thermal conductivities of polycrystalline AIN have been: (1) reduction of powder impurities, namely, oxygen and silicon, (2) appropriate selection of sintering additives, and (3) utilization of controlled sintering conditions. Each of these areas will be reviewed.

As with all dielectric solids, impurities in aluminum nitride's crystalline lattice have a strong detrimental effect on its thermal conductivity. Key among these impurities is lattice oxygen. Based upon his work with single crystal, Slack proposed that oxygen atoms enter the AIN lattice in the nitrogen sites $[4,6]$. This substitutional process leads to the creation of one aluminum vacancy $\left(V_{A I}\right)$ for every three oxygens, which are incorporated into the lattice:

$\mathrm{Al}_{2} \mathrm{O}_{3} \stackrel{\mathrm{AlN}}{\longrightarrow} 3 \mathrm{O}_{\mathrm{N}}+2 \mathrm{Al} l_{\mathrm{Al}}+\mathrm{V}_{\mathrm{Al}}$

It is the resulting mass difference the occupied $\mathrm{Al}$ sites and the $V_{A l}$ sites which generates lattice anharmonicity in AlN. It is widely accepted that the vacancies associated with the soluble oxygen are the most critical factor causing phonon scattering and thus the key defect which limits the thermal conductivity of AIN [3-4,6,9].

The distribution of oxygen impurities in AIN powders is a function of the powder's synthesis method [10]. For powders prepare by carbothermal reduction of aluminum oxide, oxygen remains from incomplete conversion of $\mathrm{Al}_{2} \mathrm{O}_{3}$ and/ or impurities such as silica. This residual oxygen is identified as lattice oxygen. The second source of powder oxygen is an artifact from processing "crude" AlN into finished powder. For example, the carbothermal process generally involves an additional oxidation step to remove excess carbon. This step generates an oxygen rich layer on the surface of AIN powder.

Because AIN is a highly covalent material, the pressureless sintering of pure AIN (oxygen $<1 \mathrm{wt} \%$ ) is difficult. Enhanced densification of AIN is achieved via reaction of the inherent surface oxide on AIN powders with select sintering additives, typically alkaline earth or rare earth oxides, carbides or 


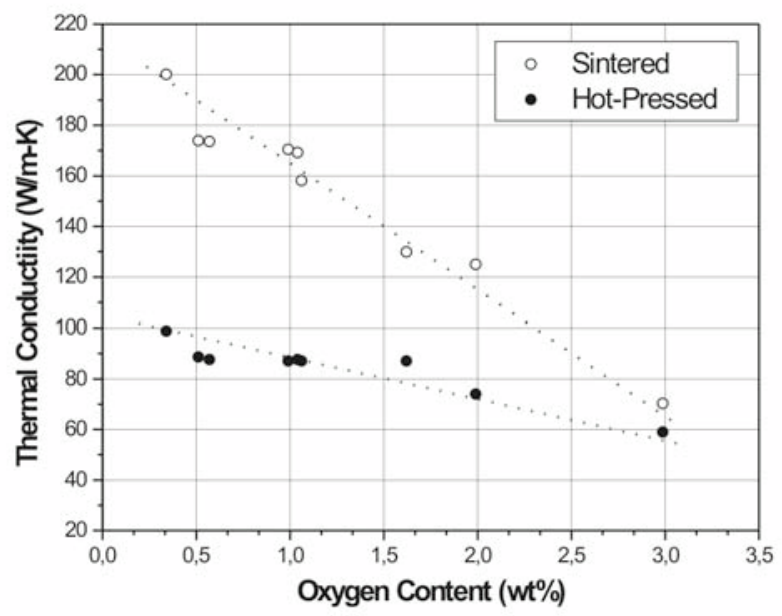

Figure 4: Relationship between oxygen content of AlN starting powder and the thermal conductivity. (open circle) Sintered, $3 \mathrm{wt} \%$ of $\mathrm{Y}_{2} \mathrm{O}_{3}$ at $1900{ }^{\circ} \mathrm{C}$ for 2 hours, (solid circle) Hot-Pressed, $0 \mathrm{wt} \%$ of $\mathrm{Y}_{2} \mathrm{O}_{3}$ at $1800{ }^{\circ} \mathrm{C}$ under $400 \mathrm{~kg} / \mathrm{cm}^{2}$ for 1 hour.

[Figura 4: Relação entre a quantidade de oxigênio dos pós de AlN e a condutividade térmica. (círculos abertos) Sinterizadas, $3 \mathrm{wt} \%$ de $\mathrm{Y}_{2} \mathrm{O}_{3}$ a $1900{ }^{\circ} \mathrm{C}$ por 2 horas, (circulos fechados) Prensada a quente, $0 \%$ em peso de $\mathrm{Y}_{2} \mathrm{O}_{3}$ a $1800{ }^{\circ} \mathrm{C}$ sob $400 \mathrm{~kg} / \mathrm{cm}^{2}$ por 1 hora].

fluorides [3,10-15]. These sintering additives not only promote densification via formation of intermediate liquid phases, but they can also enhance the thermal conductivity of AIN. The effectiveness of the sintering additives for purification of the AlN lattice can be analyzed from both a thermodynamic and a kinetic perspective [3]. From the thermodynamic perspective, the greater the affinity an additive has for oxygen, the greater will be the degree of purification of the AIN lattice.

Fig. 4 compares the thermal conductivity of polycrystalline AlN specimens which were prepared by pressure-assisted densification (without sintering additives) and pressureless sintering (using $3 \mathrm{wt} \% \mathrm{Y}_{2} \mathrm{O}_{3}$ as the sintering additive) [11].

In both cases, the thermal conductivity increased with decreasing oxygen content of the raw powder; however, the effect was most dramatic for the specimens densified using the $3 \mathrm{wt} \%$ $\mathrm{Y}_{2} \mathrm{O}_{3}$ sintering additive. Although this study demonstrated the importance of powder oxygen, it did not emphasize that for any given powder there is an optimal sintering additive level where maximum thermal conductivity is achieved. Such effects were recently demonstrated by comparing by comparing the thermal conductivity of a series of powders which were formulated with various $\mathrm{Y}_{2} \mathrm{O}_{3}$ levels, Fig. 5 [10].

In that study, the surface and lattice oxygen levels of the AlN powders varied, respectively, from 0.40 to $0.63 \mathrm{wt} \%$ and the $\mathrm{Y}_{2} \mathrm{O}_{3}$ loading increased, the resulting secondary phases became more yttria rich, i.e., the phase chemistry shifted from $\mathrm{Y}_{3} \mathrm{Al}_{5} \mathrm{O}_{12}(3: 5)$ to $\mathrm{YAlO}_{4}(1: 1)$ to $\mathrm{Y}_{4} \mathrm{Al}_{2} \mathrm{O}_{9}(4: 2)$. Under the sintering parameters of the analysis, optimal thermal conductivities were achieved when $\mathrm{Y}_{4} \mathrm{Al}_{2} \mathrm{O}_{9}$ was present as the grain boundary phase. When the $\mathrm{Y}_{2} \mathrm{O}_{3}$ levels were too high, densification was hindered and the resulting thermal conductivities decreased. The results indicate that the distribution of sintered oxygen is strongly correlated with the relative concentrations of the powder's lattice and surface oxygen. As predicted, the powders with the lowest lattice oxygen concentrations exhibited the highest thermal conductivities. Hence, depending upon the surface oxygen contents, different yttria levels were required higher for optimal thermal conductivities, i.e., higher surface oxygen contents required higher sintering additive levels than did low surface oxygen powders.

In addition to powder chemistry, sintering conditions have a dramatic effect on thermal conductivity, Fig. 6 [10]. Numerous studies have verified that higher sintering temperatures, longer sintering times, and slower cooling rates result in higher thermal conductivities [3,10-14].

These higher thermal conductivities are primarily attributed to enhanced kinetics of oxygen purification. Direct

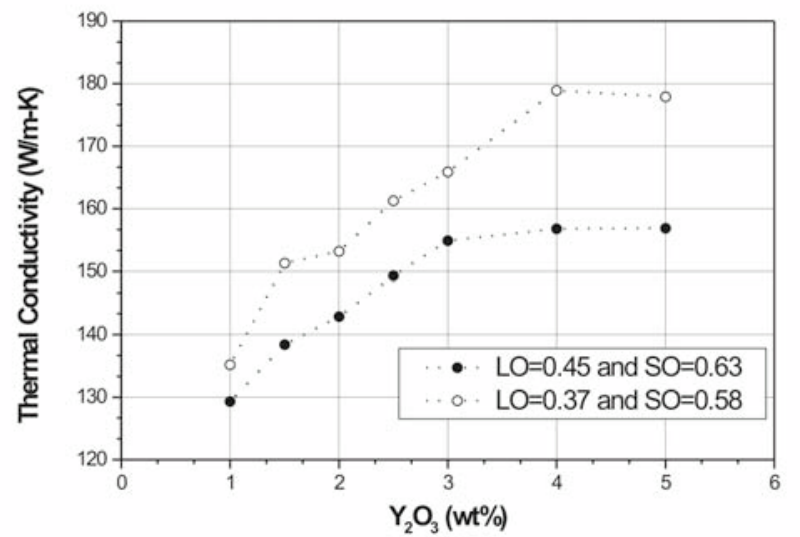

Figure 5: Thermal conductivity dependence on $\mathrm{Y}_{2} \mathrm{O}_{3}$ addition and powder chemistry. $\mathrm{LO}=$ Lattice Oxygen, and $\mathrm{SO}=$ Surface Oxygen. [Figura 5: Dependência da condutividade térmica em relação a adição de $\mathrm{Y}_{2} \mathrm{O}_{3}$ e química dos pós. $L O=$ Oxigênio na rede, e $\mathrm{SO}=$ Oxigênio na superficie].

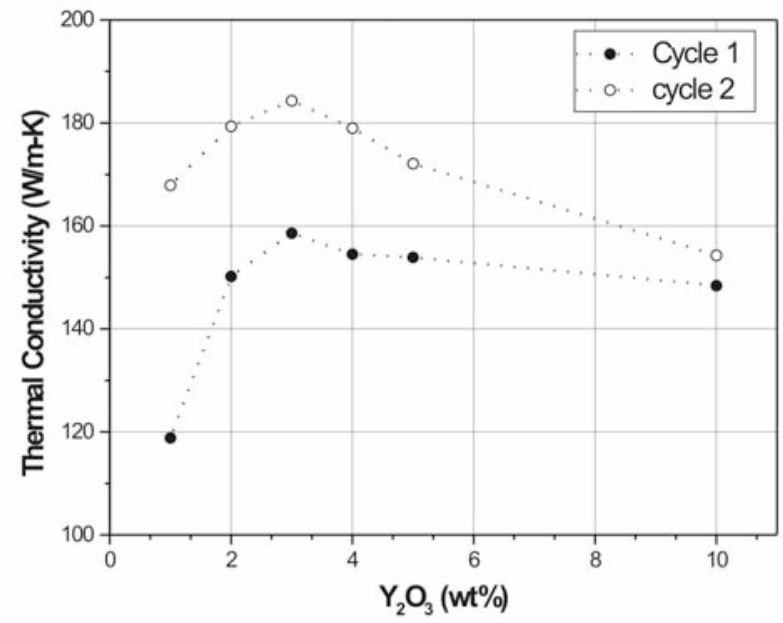

Figure 6: Thermal conductivity dependence on $\mathrm{Y}_{2} \mathrm{O}_{3}$ addition and sintering cycle. Cycle 1: $1850{ }^{\circ} \mathrm{C}, 2$ hours, $50{ }^{\circ} \mathrm{C} / \mathrm{min}$ cooling rate and Cycle 2: $1850{ }^{\circ} \mathrm{C}, 3$ hours, $1{ }^{\circ} \mathrm{C} / \mathrm{min}$ cooling rate.

[Figura 6: Dependência da condutividade térmica em relação a adição de $\mathrm{Y}_{2} \mathrm{O}_{3}$ e ciclo de sinterização. Ciclo 1: $1850{ }^{\circ} \mathrm{C}, 2$ horas, $50^{\circ} \mathrm{C} /$ min taxa de resfriamento e Ciclo 2: $1850^{\circ} \mathrm{C}, 3$ horas, $1{ }^{\circ} \mathrm{C} /$ min taxa de resfriamento]. 


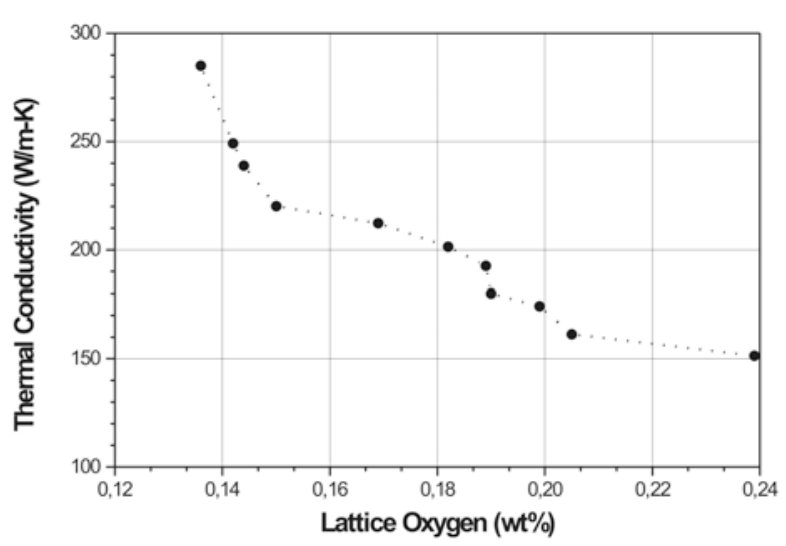

Figure 7: Thermal conductivity dependence on sintering lattice oxygen.

[Figure 7: Dependência da condutividade térmica em relação ao oxigênio da rede].

measurements of sintered lattice oxygen were recently made on a series of AIN specimens. The lattice oxygen values were obtained via electron microprobe analysis of individual AIN grains within the sintered pellets. The specimens were fabricated as a part of a statistically designed experiment to test the relative role of various sintering parameters, e.g., eating rate, sintering temperature, sintering time, and cooling rate, on AlN's properties. The room temperature thermal conductivity of the specimens ranged from 130-285 W/m-K. In overall agreement with theory, the thermal conductivity increased with decreasing lattice oxygen, Fig. 7.

Is should be noted that other impurities which generate lattice vacancies will also lead to a reduction in AlN's thermal conductivity. For instance, Baranda [7] has found that silica impurities produce such an effect. The thermal conductivity of AIN dramatically decreased with increasing silica level $[7,15]$. Similar to Slack's treatment of oxygen, Baranda proposed the following substitution reaction for silica into AIN:

$$
\mathrm{SiO}_{2} \stackrel{A I N}{\longrightarrow} 2 \mathrm{O}_{N}+\mathrm{Si}_{A l}+V_{A l}
$$

In his analysis, Baranda found that silica appeared to go into limited solution in the AIN grains, after which, continued additions resulted in the formation of polytypoids derived from the basic $2 \mathrm{H}$ AIN structure. These results are consistent with the early work of Komeya [16].

As long as the second phase is well distributed and the AlN phase is contiguous, then the morphology of the second phase is expected to have a minor effect on the thermal conductivity [3]. Indeed, this is the case when $\mathrm{Y}_{2} \mathrm{O}_{3}$ is the sintering additive. In sharp contrast, when $\mathrm{CaO}$ is incorporated as a sintering additive, the resulting calcium aluminates effectively wet the grain boundaries and disrupt the contiguous nature of the AIN matrix [7,15]. The net result is an overall reduction in the thermal conductivity of the AIN ceramic, Fig. 8. Thus, even though $\mathrm{CaO}$ is an effective oxygen getter, its influence on the microstructure is sufficient to override the net effect of lattice oxygen purification.

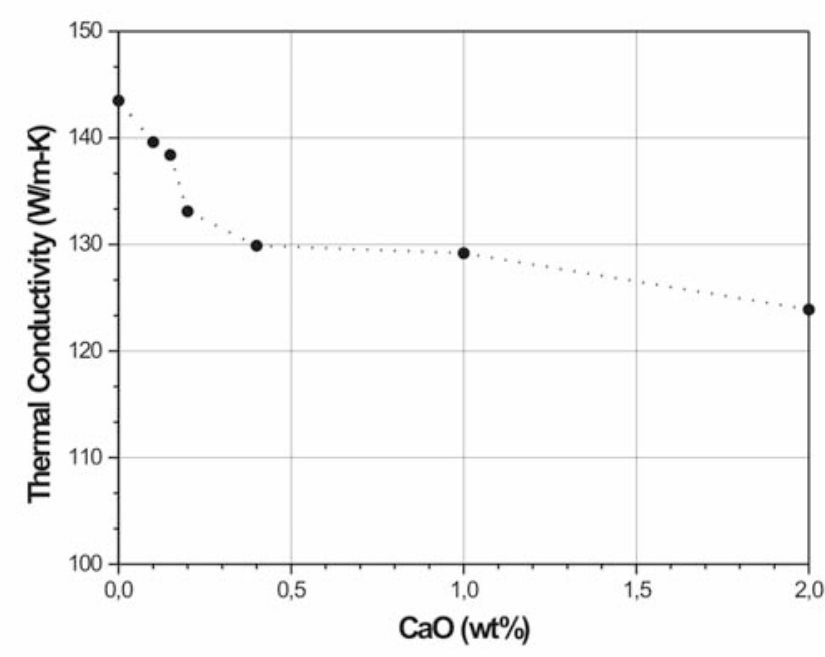

Figure 8: Thermal conductivity dependence on $\mathrm{CaO}$ additions. [Figure 8: Dependência da condutividade térmica em relação à adição de oxigênio].

\section{SUMMARY}

From thus study we can conclude that:

- The room temperature thermal conductivity values of polycrystalline AIN ceramics are reported to range from as low as $17 \mathrm{~W} / \mathrm{m}-\mathrm{K}$ to as high as $285 \mathrm{~W} / \mathrm{m}-\mathrm{K}$.

- The variation which is observed is strongly dependent upon the purity of the starting materials and the details of the fabrication process. The technological areas which have contributed most significantly to enhanced thermal conductivities of polycrystalline AlN have been: (a) reduction of powder impurities, namely oxygen and silicon, (b) appropriate selection of sintering additives, and (c) utilization of controlled sintering conditions.

- Enhanced densificantion of AIN is achieved via reaction of the inherent surface oxide on AIN powders with select sintering additives. These sintering additives not only promote densification via formation of intermediate liquid phases, but they can also enhance the thermal conductivity of AIN. From a thermodynamic perspective, the greater the affinity a sintering additive has for oxygen, the greater is its ability to purify the lattice.

- Both $\mathrm{Y}_{2} \mathrm{O}_{3}$ and $\mathrm{CaO}$ have been found to be effective sintering additives. Reduced lattice oxygen is also observed after extended annealing times at elevated temperatures. This reduction is attributed to enhanced diffusion of defect-centers which cause phonon scattering. Thus, lattice purification is also dependent upon the kinetics of the sintering process.

\section{ACKNOWLEDGEMENTS}

The authors would like to thank The Center for Ceramic Research, USA for providing the laboratory facilities for sintering, characterization and thermal conductivity measurements of AlN specimens. Special thanks are also extended to Universidade Católica de Goiás (UCG), Brazil, for financial support. 


\section{REFERENCES}

[1] W. D. Kingery, H. K.Bowen, D. R. Uhlmann, Introduction to Ceramics, Chapter 12. Thermal properties, John Wiley \& Sons, New York, (1976) 583.

[2] J. F. Nye, Physical Properties of Crystals, Chapter XI Thermal and Electrical Conductivity, Clarendon Press, Oxford, (1985) 195.

[3] A. V. Virkar, T. B. Jackson, R. A Cutler, J. Am. Ceram. Soc. 72 (1989) 2031.

[4] G. A Slack, R. A Tanzilli, R. O Pohl, J. W. Vandersande, J. Phys. Chem. Solids 48 (1987) 641.

[5] B. Abeles, Phys. Rev. 131 (1962) 1906.

[6] G. A Slack, J. Phys. Chem. Solids 34 (1973) 321-335.

[7] P. S. de Baranda, "The effect of Calcia and Sílica on the Thermal Conductivity of Aluminum Nitride Ceramics, PhD. Thesis, Rutgers, The State University of New Jersey, (1991). [8] P. Procter, J. Sol, IEEE Trans. CHMT 14 (1991) 708.

[9] J. H. Harris, R. A Youngman, R. G. Teller, J. Mater. Res 5
(1990).

[10] T. A Guiton, J. E. Volmering, K. K. Killinger, Mat. Res. Soc. Symp. Proc. 271 (1992) 851.

[11] F. Miyashiro, N. Iwase, A Tsuge, F. Ueno, M. Nakahashi, and T. Takahashi, IEEE Trans. Comp. Hybrids, Manuf. Tech. 13 (1990) 313.

[12] K. Watari, M. Kawamoto, K. Ishizaki, J. Mater. Sci. 26 (1991) 4727.

[13] F. Ueno, A. Horiguchi, in Euro- Ceramics Vol. 1 pp 383387, ed by G. de With, R. A Terpstra, R. Metselaar, Elsevier Applied Science, London (1994).

[14] T. Yagi, K. Shinozaki, N. Mizutani, M. Kato, Y. Sawada, Nippon Ceramics Kyokai Gakujutsu Robunshi 97 ( 1989) 13721378.

[15] A. K. Knudsen, et al., IMC 1992 Proceedings, A. K. Yokohama, 3-5 (1992) 270-274.

[16] K. Komeya, H Inoue, A . Tsuge, J. Am. Ceram. Soc. 57 (1974) 411-412.

(Rec. 30/01/04, Ac. 01/04/04) 